\title{
Ciclo reproductivo y reclutamiento del mejillón Mytilus edulis platensis en Bahía San Julián (Santa Cruz, Argentina)
}

\section{Reproductive cycle and recruitment of the mussel Mytilus edulis platensis in Bahía San Julián (Santa Cruz, Argentina)}

\author{
Alicia Sar ${ }^{1}$, Juan Pablo Martin ${ }^{1}$, Raúl Fernández ${ }^{1}$ y Carlos Caminos ${ }^{1}$ \\ ${ }^{1}$ Instituto de Ciencias del Ambiente, Sustentabilidad y Recursos Naturales (ICASUR) \\ Unidad Académica San Julián, Universidad Nacional de la Patagonia Austral. \\ Colón y Sgto. Cabral, Puerto San Julián, Santa Cruz. \\ aliciamsar@yahoo.com
}

Recibido: 18/12/17. Aceptado: 14/05/18

\begin{abstract}
RESUMEN
El presente trabajo tiene por objetivo brindar información sobre el ciclo reproductivo y reclutamiento del mejillón Mytilus edulis platensis, una especie de importancia comercial, en bancos naturales intermareales de una localidad de la Provincia de Santa Cruz. Para ello, entre el 2013 y 2015 se realizaron muestreos biológicos y censos poblacionales estacionales y mensuales de la especie en un banco natural sobre sustrato fangoso y en otro asentado sobre sustrato rocoso en el interior de la Bahía San Julián. En el laboratorio, se determinó el largo total de los individuos, parte de los cuales fue luego procesado mediante técnicas histológicas convencionales para conocer el grado de madurez y desarrollo gonadal. Se realizaron también muestreos mensuales de zooplancton con el fin de detectar la época de mayor concentración de larvas de mejillón en el agua. Como resultado, se observó un alto grado de sincronismo en los estadios de madurez gonadal entre los individuos de Mytilus edulis platensis en la Bahía San Julián; la evacuación de gametas se produjo desde fines de primavera hasta fines de verano; las larvas presentaron su mayor abundancia en el plancton durante el mes de febrero, cuando la temperatura del agua alcanzó su valor máximo; los juveniles se incorporaron a la población principalmente durante el verano y el otoño; la abundancia de juveniles fue generalmente irregular a lo largo del tiempo y poco predecible en los bancos de Bahía San Julián.
\end{abstract}

Palabras clave: ciclo reproductivo, reclutamiento, mejillón, Mytilus edulis platensis, Patagonia austral.

\begin{abstract}
The purpose of this report is to provide information on the reproductive cycle and recruitment of the mussel Mytilus edulis platensis, a species of commercial importance, in intertidal natural banks of a locality in the province of Santa Cruz. Between 2013 and 2015 biological sampling and seasonal and monthly population censuses of the species were conducted in a natural bank on muddy substrate and in another settled on rocky substrate in the interior of Bahía San Julián. In the laboratory, the total length of the individuals was determined, part of which was then processed by conventional histological techniques to determine the degree of maturity and gonadal development. Monthly zooplankton surveys were also carried out in
\end{abstract}


order to detect the period of greatest concentration of mussel larvae in the water. As a result, a high degree of synchronism was observed in the gonadal maturity stages among individuals of Mytilus edulis platensis in Bahía San Julián; evacuation of gametes occurred from late spring until late summer; the larvae reached their greatest abundance in the plankton during February, when water temperature reached its maximum value; juveniles were incorporated into the population mainly during summer and autumn; abundance of juveniles was generally irregular over time and little predictable in the banks of Bahía San Julián.

Key words: reproductive cycle, recruitment, mussel, Mytilus edulis platensis, Southern Patagonia.

\section{INTRODUCCION}

El conocimiento de la dinámica poblacional y de los patrones reproductivos de las especies marinas de importancia comercial, constituye una herramienta clave para el manejo de su explotación. Los moluscos bivalvos son los componentes faunísticos más relevantes en las comunidades bentónicas costeras de la Patagonia y, dado que constituyen un recurso de alto valor para el sector pesquero artesanal y la acuicultura, tienen una gran importancia socioeconómica. Sin embargo, existen aspectos fundamentales de la historia de vida (desove, supervivencia y dispersión larvaria, asentamiento, crecimiento y supervivencia postasentamiento) de algunas de las especies de importancia comercial que aún permanecen sin elucidar.

Las poblaciones naturales de los organismos bentónicos como los mejillones, están estructuradas como metapoblaciones, con subpoblaciones interconectadas por la dispersión de larvas pelágicas. Las subpoblaciones locales poseen una dinámica particular, ya que están abiertas al reclutamiento de individuos originados en otras regiones, y también funcionan como fuentes de larvas que darán origen o contribuyen a otros bancos. Tanto la formación de un nuevo banco como la expansión de uno preexistente son expresiones de un fenómeno a mesoescala, que refleja procesos en los cuales se involucran la transición de dos estadios (larvas pelágicas y reclutas) que ocurren a una escala mucho menor.

Los bancos intermareales del mejillón Mytilus edulis platensis d'Orbigny, 1846 de la costa de Santa Cruz son explotados artesanalmente debido a su fácil accesibilidad y el bajo costo de extracción, sustentando una actividad pesquera de magnitud moderada. La explotación racional y el cultivo del recurso llevan implícitos el conocimiento integral de su biología, principalmente en lo que respecta a la reproducción de la especie y el reclutamiento de individuos a la población. Este conocimiento es importante para definir, por ejemplo, la mejor época para colocar colectores de semilla en el mar, o para disminuir el riesgo y la impredictibilidad de la fase de captación. Por otra parte, el conocimiento de la dinámica poblacional y de los patrones reproductivos de esta especie de importancia comercial constituyen una herramienta clave para el manejo de su explotación.

El presente estudio es resultado del Proyecto de investigación "Ciclo reproductivo y reclutamiento del mejillón en bancos naturales de Santa Cruz (Argentina)" (PI 29D/051) de la Universidad Nacional de la Patagonia Austral, cuyo objetivo general fue conocer el ciclo reproductivo y época de mayor reclutamiento del mejillón Mytilus edulis platensis en bancos naturales intermareales de una localidad de la provincia de Santa Cruz, siendo los objetivos específicos: describir el ciclo de maduración gonadal del mejillón a lo largo del año en Bahía San Julián; conocer las épocas de desove y de mayor concentración de larvas en el plancton, e identificar las épocas de mayor reclutamiento de postlarvas en los bancos naturales intermareales de la bahía. 
La costa de la Bahía San Julián posee abundantes poblaciones de mejillón Mytilus edulis platensis, una especie que ha sido señalada como de gran interés para la maricultura en la región. El principal inconveniente con el que se enfrentan actualmente los productores es la disponibilidad de fuentes de semilla adecuadas para su cultivo, existiendo dos alternativas de solución a esta problemática. La primera es la posibilidad de obtener semilla a partir del reclutamiento en bancos naturales; la segunda, es la captación de semilla utilizando colectores artificiales. En este sentido, el presente estudio aporta información sobre el comportamiento reproductivo del mejillón (descripción del ciclo reproductivo y épocas de reclutamiento de postlarvas) en bancos naturales intermareales, que es de utilidad para la acuicultura local.

La información obtenida en este estudio es de interés por su aplicación en futuros emprendimientos de cultivo de mejillón, ya que permite conocer el momento y lugar apropiados para colocar colectores que permitan la captación de semilla. Esta información es de interés también para los organismos gubernamentales de aplicación, relacionados con la implementación de estrategias de manejo racional, que permitan tanto la conservación de los bancos naturales de mitílidos como los emprendimientos productivos que puedan desarrollarse en la región.

\section{Características biológicas de la especie}

Los mejillones son moluscos bivalvos pertenecientes a la familia Mytilidae, se encuentran entre los moluscos marinos más comunes y son dominantes en muchos ecosistemas litorales y sublitorales de aguas someras. Su importancia económica, ecológica, biológica y evolutiva ha llevado a que la familia sea una de las mejor estudiadas entre los bivalvos (Zaixso, 1999).

El mejillón Mytilus edulis platensis es una especie sésil, que vive adherido a un sustrato y habita, en ocasiones, en áreas de la costa de fácil acceso. Por esta razón, ha sido utilizado desde tiempos remotos como alimento por las poblaciones humanas que habitan la costa. En Argentina, se extrae a escala familiar y se lo pesca en forma artesanal en diversas regiones. Estos moluscos viven en manojos o "chofas", adhiriéndose a sustratos rocosos en el mediolitoral e infralitoral, y en sustratos arenosos del infralitoral y circalitoral, donde conforman extensos y densos bancos entre los 10 y los 80 metros de profundidad (Lasta et al., 1998). En la costa de Santa Cruz existen poblaciones dispersas que conforman bancos intermareales naturales sobre sustratos rocosos y también en fondos blandos fangosos, como los de la Bahía San Julián.

El interés creciente en la explotación sustentable del mejillón ha dado lugar a diversos estudios biológico-pesqueros. Parámetros de su ciclo biológico han sido estudiados en aguas abiertas, a $60 \mathrm{~m}$ de profundidad, en la provincia de Buenos Aires (Penchaszadeh, 1974, 1983), en poblaciones costeras dentro de los Golfos San Matías (Morsan y Zaidman, 2009; Oehrens Kissner y Kroeck, 2006) y San José (Bala, 1989, 1996) y en poblaciones intermareales de Península Valdés (Trancart, 1978). En la provincia de Santa Cruz, esta especie es considerada de interés para la maricultura, sin embargo, son pocos los estudios realizados sobre su dinámica poblacional en el litoral santacruceño.

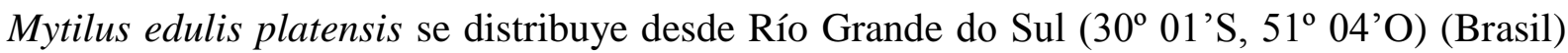
hasta Tierra del Fuego. En la costa argentina, se encuentran bancos de mejillones ocupando principalmente sustratos rocosos del mesolitoral e infralitoral, constituyendo a menudo franjas paralelas a la costa a diferentes rangos de profundidades (desde 10 a $80 \mathrm{~m}$ ), como sucede en la provincia de Buenos Aires (Penchaszdeh, 1974). En el Golfo San Matías (Río Negro) los bancos sometidos a explotación son más costeros y se encuentran a profundidades variables entre 7 y 35 m (Morsán, 2007), mientras que en el Golfo San José (Chubut) se encuentran en aguas someras desde el mesolitoral hasta $20 \mathrm{~m}$ de profundidad en sustratos arenosos (Bala, 1989). Para el infralitoral del Golfo San José se ha señalado la posibilidad de una vía de 
sucesión entre éstos y los bancos mixtos de cholga-mejillón, ambos sobre ambientes similares en cuanto a sustrato, profundidad y exposición al oleaje, lo que podría indicar que ambos tipos de bancos son diferentes estados temporales de un mismo ensamble (Zaixso, 2004). En el litoral de Puerto Deseado (Santa Cruz), el piso mesolitoral de sustrato rocoso es muy extenso, y su característica más saliente es la presencia del mitílido Perumytilus purpuratus (Lamarck, 1819). Entre el mesolitoral inferior y el piso infralitoral existe una zona de transición donde se hallan especies de ambos pisos; esta zona suele presentarse en áreas de fuerte pendiente donde abundan los moluscos bivalvos del género Aulocomya y Mytilus. Bala (1989) cita la presencia de Mytilus edulis platensis a $30 \mathrm{~m}$ en la costa de Santa Cruz, entre Cabo Blanco y la Ría Deseado. En la costa de Tierra del Fuego, el mejillón es la especie más abundante en sustratos rocosos cerca de Ushuaia (Zaixso et al., 1978). En la Isla de los Estados, también de litoral rocoso, se hallan asociaciones de Aulacomya ater y Mytilus chilensis (Hupe, 1854) en el nivel inferior del piso mesolitoral (Kühneman, 1976).

Los mejillones son organismos dioicos (sexos separados). Macroscópicamente es posible observar un dimorfismo sexual en aquellos individuos con un alto grado de madurez, donde la gónada se observa de un color anaranjado en las hembras y de color crema brillante en los machos (Lasta et al., 1998). La gónada se desarrolla en el manto de forma difusa (ya que no es un órgano discreto) y puede extenderse hacia la masa visceral y hacia la cavidad paleal en estados de máxima madurez gonadal (Gosling, 1992). Microscópicamente, los folículos gonadales se encuentran separados y rodeados por tejido conjuntivo de reserva, constituido por células adipogranulares y células vesiculares. Las células de las líneas germinales surgen del epitelio de estos folículos y a medida que progresa la gametogénesis aumenta el diámetro de los folículos gonadales, y los distintos tipos de células de la línea germinal ocupan el lumen folicular (Villalba, 1995). El desarrollo de las células sexuales puede verse como una serie de cambios morfológicos que ocurren durante el proceso de maduración (Lubet, 1959; Bala, 1991) y puede ser observado fácilmente mediante cortes histológicos. La fecundación es externa y los individuos de una misma población tienen un notable sincronismo en la emisión de gametas. Cuando las gametas están maduras, son liberadas al agua donde ocurre la fecundación que dará lugar al estadio larval pelágico. La larva pelágica sufre una metamorfosis para dar lugar a la fase de postlarva que se asienta sobre el sustrato bentónico.

\section{Área de estudio}

La Bahía San Julián se encuentra localizada en la costa central de la provincia de Santa Cruz y se ubica entre los $68^{\circ} 50^{\prime} 01^{\prime \prime}$ y los $67^{\circ} 35^{\prime} 50^{\prime \prime}$ de longitud oeste y entre los $49^{\circ} 00^{\prime} 12^{\prime \prime}$ y los $49^{\circ} 47^{\prime}$ 02" de latitud sur (Fig. 1). Tiene una extensión de $20 \mathrm{~km}$ de largo y 8,8 km de ancho máximo, una profundidad máxima de 35 metros y una boca relativamente estrecha de aproximadamente 700 metros de ancho. Recibe aguas frías de origen subantártico y de salinidad relativamente baja aportadas por la Corriente Costera Patagónica, una rama de la Corriente de Malvinas. La salinidad del agua en el interior de la bahía es de entre 33 y 34 por mil y su temperatura oscila entre $5{ }^{\circ} \mathrm{C}$ (invierno) y $14{ }^{\circ} \mathrm{C}$ (verano). El régimen de mareas es de tipo macromareal semidiurno, con una amplitud máxima de $8,93 \mathrm{~m}$ y una amplitud media de 6,15 m (Falabella et al., 2009; SHN, 2009).

En la costa de la bahía predominan las planicies de marea fangosas constituidas principalmente por fango (limo+arcilla) y arena fina, con importantes extensiones de marismas en el nivel intermareal superior, donde predomina la halófita Sarcocornia perennis, y comunidades infaunales dominadas por poliquetos y pequeños bivalvos como Darina solenoides (King, 1832) y Mysella patagona Ituarte, Martin \& Zelaya, 2012 en el intermareal medio e inferior (Ituarte et al., 2012; Martin et al., 2015). Algunos sectores, con mayor 
proporción de gravas, posibilitan el desarrollo de bancos intermareales de los bivalvos mitílidos Perumytilus purpuratus, Mytilus edulis platensis y Aulacomya atra (Molina, 1782).

Los sustratos duros son escasos en el interior de la bahía y se encuentran formados por rocas sedimentarias con comunidades intermareales conformadas principalmente por bancos de mitílidos. Estos sustratos son más abundantes y alcanzan mayor desarrollo en la costa de mar abierto, aledaña a la bahía, donde sustentan una importante comunidad bentónica intermareal, caracterizada también por el desarrollo de bancos de mitílidos. En el interior de la bahía se encuentran la Isla Cormorán y la Isla Justicia, constituidas por acumulaciones de rodados y sedimento fino. El intermareal de estas islas también se encuentra poblada por importantes bancos de mitílidos, los cuales alcanzan un desarrollo particularmente importante en la Isla Justicia, asentados sobre sustrato blando de tipo fangoso, constituido por grava y un elevado contenido de limo y arcilla (Figs. 2 y 3 ).

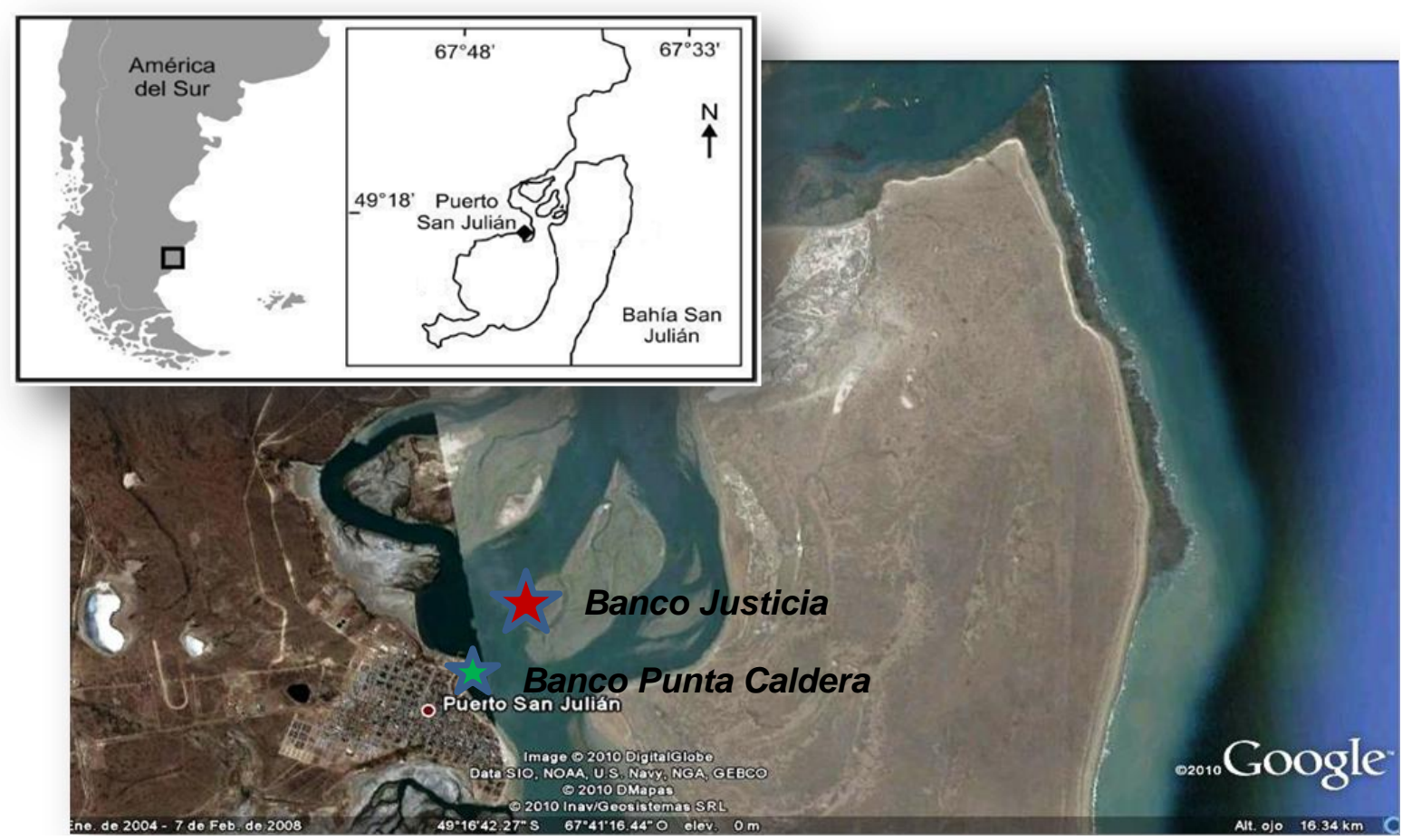

Fig. 1 Area de estudio y sitios de muestreo en la Bahía San Julián

\section{MATERIALES Y METODOS}

Entre los años 2013 y 2015 se realizaron censos estacionales de la población de Mytilus edulis platensis en bancos intermareales naturales de la Bahía de San Julián de diferentes características: sobre sustrato fangoso (Banco Justicia) y sobre sustrato rocoso (Banco de Punta Caldera) (Figs. 1, 2 y 3). A su vez, mensualmente, se recolectaron ejemplares para determinar el estadio reproductivo mediante cortes histológicos y se tomaron muestras de zooplancton para conocer la disponibilidad de larvas a lo largo del año. Paralelamente, se registró la temperatura superficial del agua utilizando una sonda multiparamétrica Horiba U10.

Los censos poblacionales se realizaron en tres niveles del intermareal: superior, medio e inferior. Se utilizó un marco de 20 x $20 \mathrm{~cm}$ de lado y una espátula para obtener cuatro muestras por nivel en cada banco estudiado (Figs. 2 y 3). Las muestras fueron llevadas al laboratorio donde se separaron los individuos de mejillón, que se contabilizaron y se midieron para registrar el largo total (Lt) de las valvas con un calibre de precisión. Los individuos 
juveniles $(<10 \mathrm{~mm} \mathrm{Lt})$ fueron medidos bajo lupa estereoscópica por medio de un ocular con escala de medición.

Las muestras de zooplancton se tomaron en forma mensual desde el muelle de operaciones del puerto de San Julián, con una red de zooplancton con malla de $150 \mu \mathrm{m}$ de abertura. Se tomaron tres réplicas por muestreo arrastrando la red en forma horizontal durante 5 minutos a paso de hombre, en la parte superior de la columna de agua. Las muestras fueron inmediatamente fijadas en solución de formol al $5 \%$ por $24 \mathrm{hs}$. y posteriormente conservadas en alcohol 70\% hasta su observación. Las larvas de mejillón fueron identificadas utilizando Ramorino y Campos (1983), medidas con un ocular graduado y contabilizadas por medio de una grilla de conteo bajo lupa estereoscópica.

Para los estudios del estado reproductivo se tomaron muestras de individuos de entre 5,5 y 6,5 $\mathrm{mm}$ de largo total (Lt). Las muestras, de 10 individuos cada una, se recolectaron estacionalmente en el Banco Justicia y mensualmente en el banco de Punta Caldera. Los individuos fueron recolectados al azar en el intermareal y trasladados in vivo al laboratorio, donde fueron lavados con agua corriente para eliminar los epibiontes y detritos depositados en las valvas. Los ejemplares fueron abiertos cortando los músculos aductores y ligamentos con un bisturí. Se separaron las partes blandas de las valvas, se les extrajo el biso y luego fueron fijadas con formol al $4 \%$ por 24 horas. Se hicieron cortes de $5 \mathrm{~mm}$ y los trozos de manto se incluyeron en cassettes para biopsias. Posteriormente, se fijaron en solución de Davidson a la cual se le agregó el 10\% del volumen final de ácido acético glacial. Los cassettes con los tejidos inmersos en el fijador se colocaron en frascos de vidrio dentro del refrigerador a $4^{\circ} \mathrm{C}$ durante 24 hs. Transcurrido este tiempo se transvasaron a etanol $70^{\circ}$. La deshidratación se realizó en forma completamente manual y se utilizó una marcha de tiempo controlado con alcoholes de graduación creciente. La inclusión en parafina (punto de fusión $57-60^{\circ} \mathrm{C}$ ) se realizó en 2 baños de 3 horas cada uno en estufa a $60^{\circ} \mathrm{C}$, el primero con una mezcla de parafina-xileno (1:1) y el segundo solo con parafina. Para la obtención de los cortes histológicos (5 a $7 \mu \mathrm{m}$ de grosor) se utilizó un Micrótomo de Rotación Arcano modelo RMT30. La tinción se realizó con Hematoxilina de Harris y Eosina "Y" en solución acuosa y luego se realizó el montaje en resina sintética para microscopía ("Canadax", BIOPUR®LB) (NOAA, 1983).

A fin de facilitar el análisis de los resultados y brindarlos de manera que puedan ser interpretados más directamente, se confeccionó una escala simple de madurez basada en los estadios de desarrollo gonadal descriptos por Villalba (1995). La escala de madurez confeccionada para este estudio incluyó los siguientes estadios:

Reposo gonadal: incluye los individuos que no tienen indicios de sexualidad. El tejido gonadal es nulo o escaso (apenas comienza a formarse) y el tejido de reserva, células vesiculares y adipogranulares presentes en el tejido conjuntivo es abundante.

- Inicio de la gametogénesis: al comienzo de esta etapa sólo se encuentran gonias en los folículos y es difícil identificar el sexo. En estados más avanzados, el lumen de los folículos está ocupado por estadios tempranos de la gametogénesis.

Proliferación: desarrollo de la gametogénesis. En esta etapa se puede diferenciar la ovogénesis de la espermatogénesis, los folículos gonadales aumentan en diámetro, en general son alargados y angostos, ocupando un porcentaje cada vez mayor del manto. El tejido de reserva es cada vez más reducido.

Maduración: en esta etapa la mayoría de los folículos han aumentado mucho su volumen y están ocupados por gametas maduras que obturan el lumen folicular. El tejido conectivo es muy escaso en los espacios interfoliculares.

Desove: se produce la evacuación de gametas. Los folículos se observan parcialmente vacíos, como consecuencia de la emisión de gametas, y las gonias que 
darán lugar a una nueva serie gametogénica aparecen en la periferia de los mismos. En esta etapa coexiste una nueva y rápida evolución de las células germinales con gametas en emisión o residuales no evacuadas.

- Post-desove: reabsorción gonadal, etapa que marca el final de la época reproductiva. Los folículos reducen su tamaño y el lumen está ocupado por gametas residuales y hemocitos que lo invaden. En el tejido conectivo se encuentran principalmente células vesiculares y un gran número de hemocitos (infiltraciones hemocitarias).

Para explorar la relación entre la abundancia de larvas de mejillón en el zooplancton y la temperatura del agua se realizó una regresión lineal simple y se aplicó una prueba de correlación calculando el coeficiente por rangos de Spearman $\left(r_{s}\right)$. Los datos de abundancia de larvas y juveniles fueron comparados entre épocas, entre bancos y entre niveles del intermareal por medio de las pruebas no paramétricas de Kruskal-Wallis y Mann-Whitney (U test) (Zar, 1996). El nivel de significancia utilizado en todas las pruebas estadísticas fue $\mathrm{p}<0.05$.
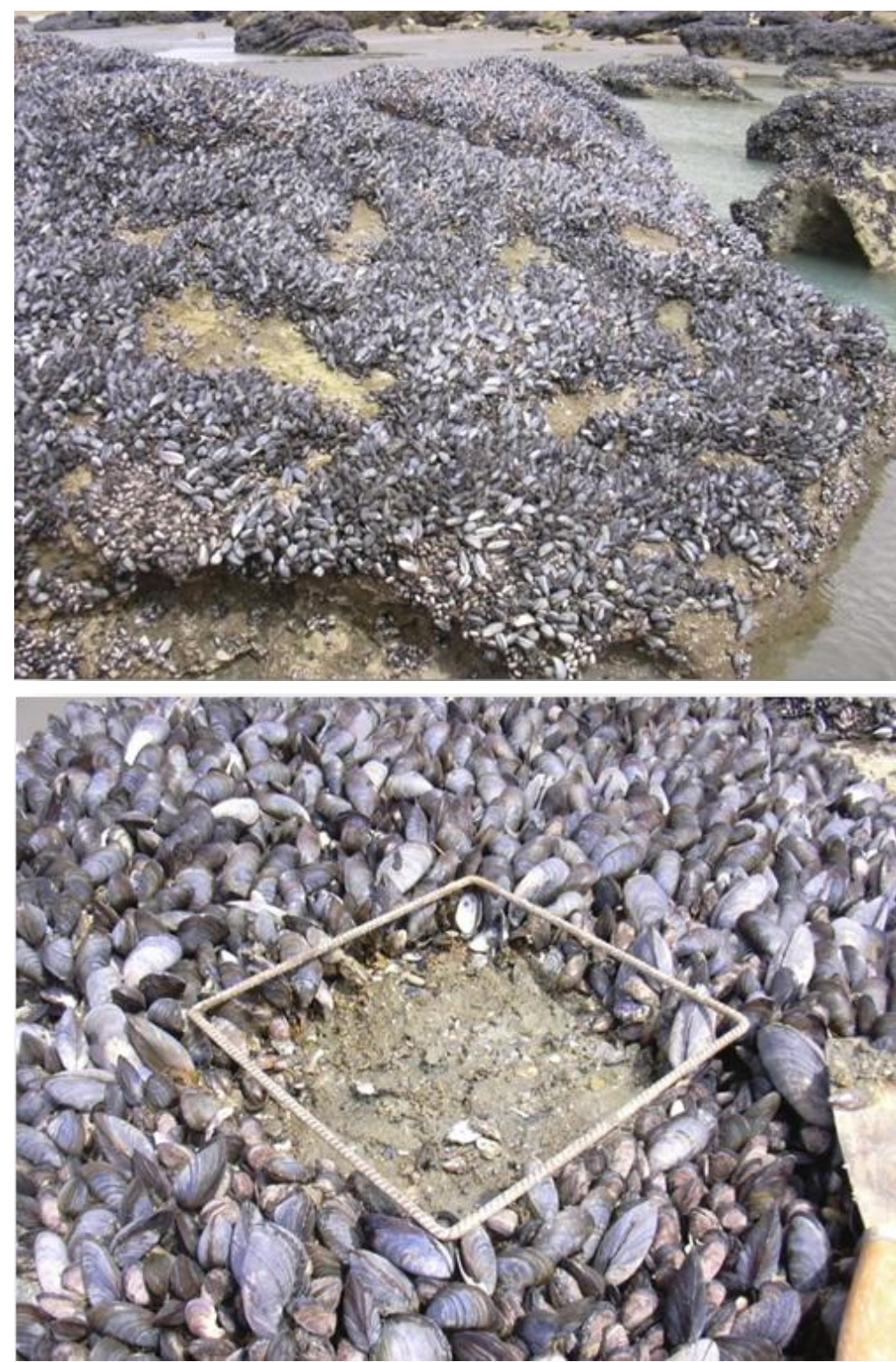

Fig. 2. Banco de mejillones sobre sustrato rocoso en Punta Caldera. 


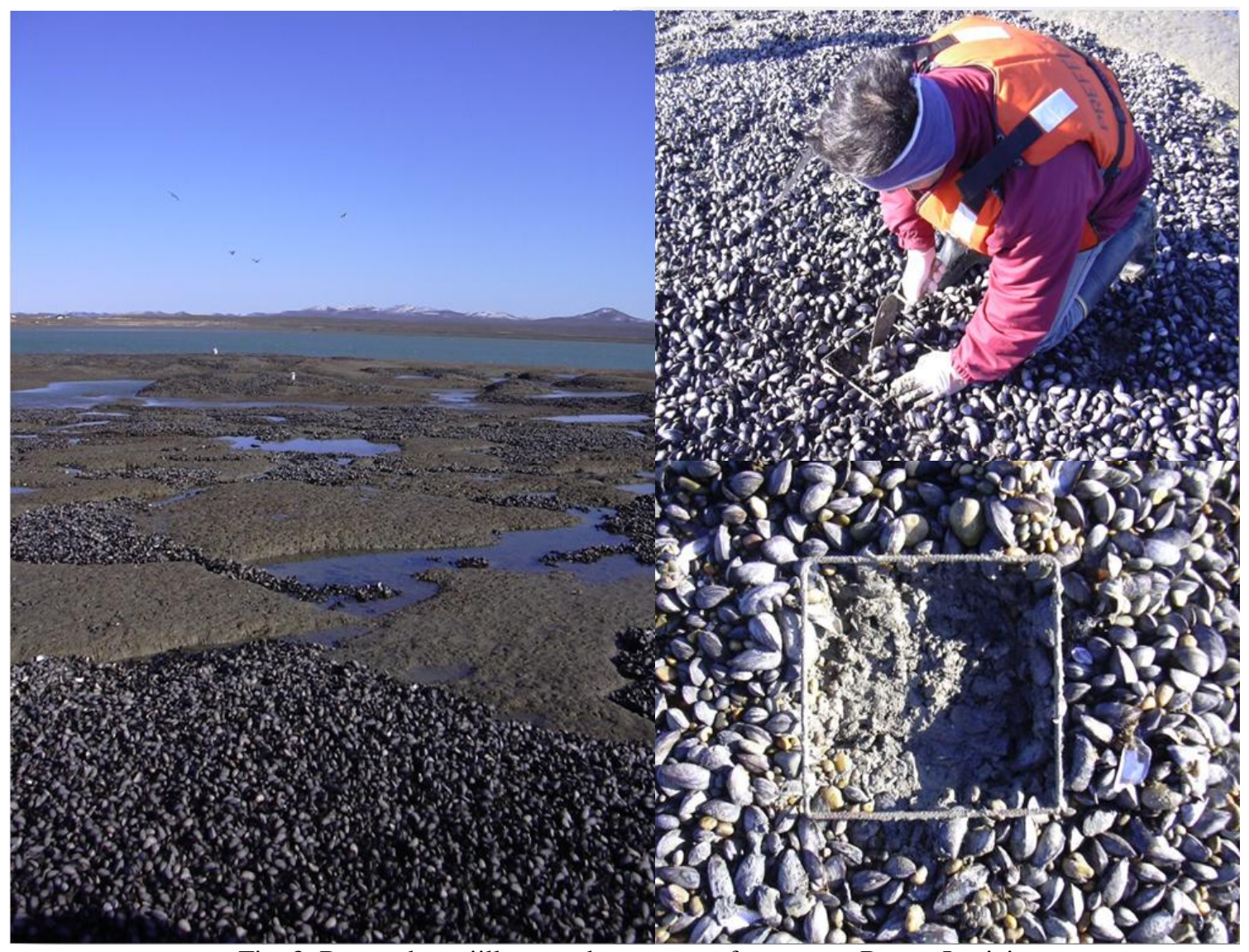

Fig. 3. Banco de mejillones sobre sustrato fangoso en Banco Justicia.

\section{RESULTADOS}

La temperatura media del agua en el muelle del puerto de San Julián durante el período de estudio alcanzó su valor más alto en el mes de febrero de $2014\left(14{ }^{\circ} \mathrm{C}\right)$ y el más bajo durante el mes de julio de 2014 (5,73 $\left.{ }^{\circ} \mathrm{C}\right)$ (Fig. 4).

La temperatura del agua medida en los bancos de mejillones mostró el mismo patrón de variación en ambos sitios estudiados, si bien con valores ligeramente más bajos durante febrero y marzo en el Banco Justicia con respecto al banco de Punta Caldera (Fig. 5).

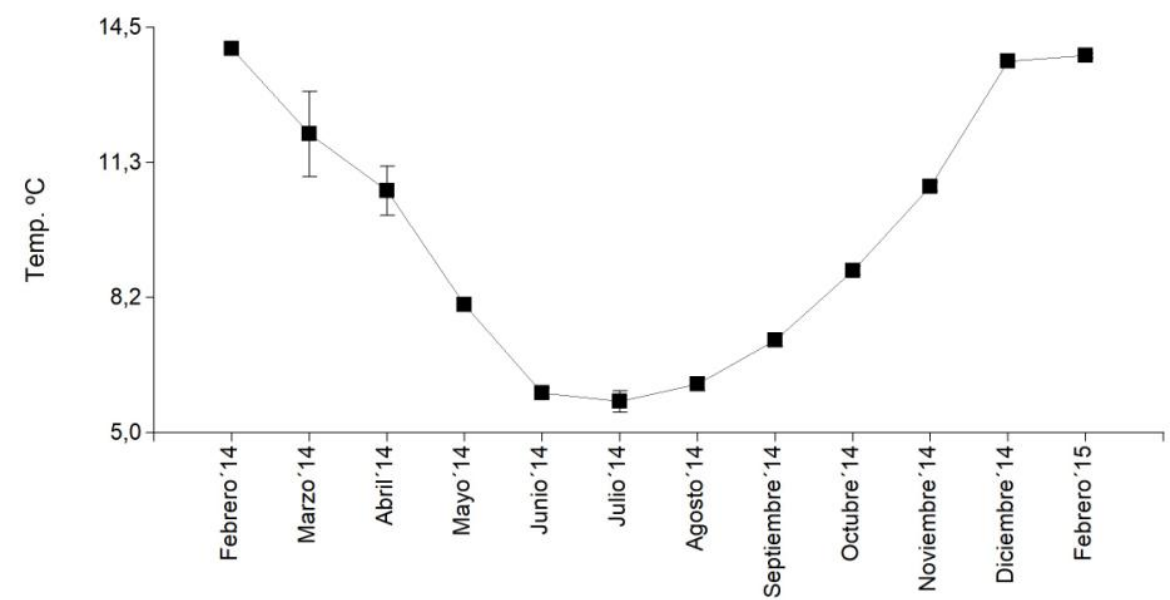

Fig. 4. Temperatura promedio ( \pm ds $)$ del agua durante el período de toma de muestras de zooplancton en el muelle de Puerto San Julián. 


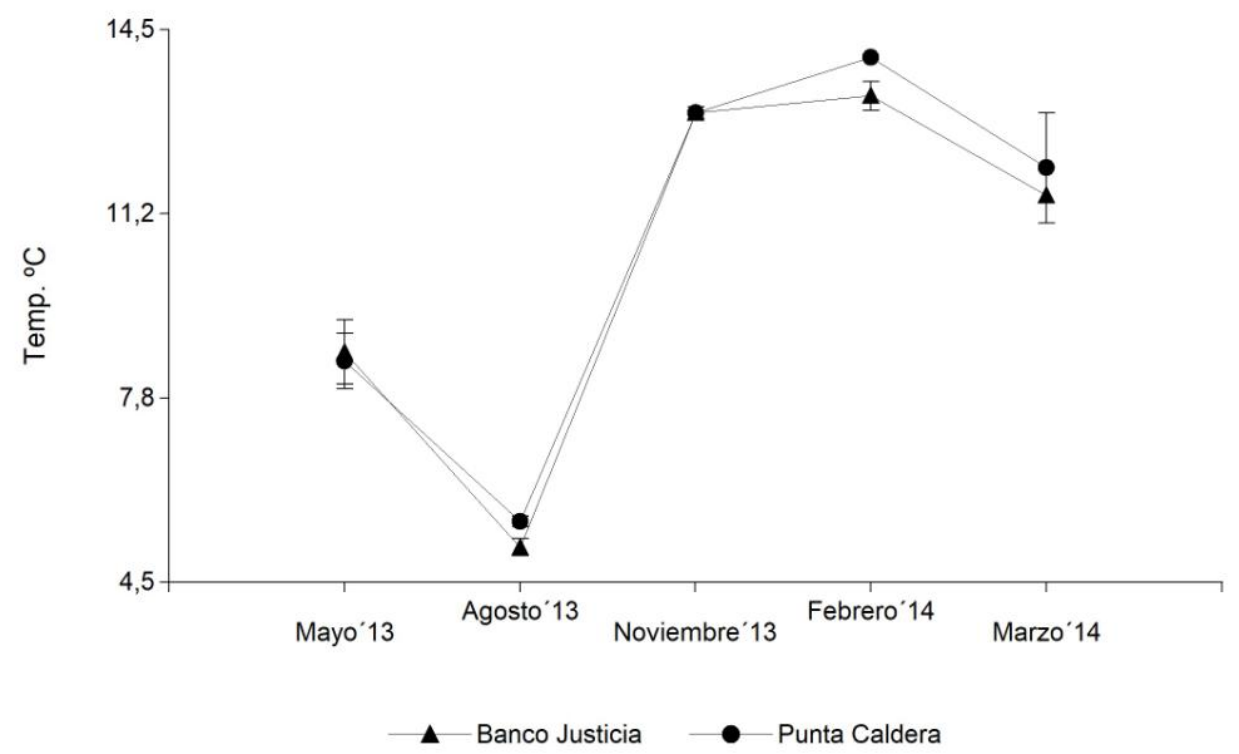

Fig. 5. Temperatura promedio $( \pm \mathrm{ds})$ del agua durante el período mayo 2013-marzo 2014 en ambos bancos estudiados.

Se realizaron análisis histológicos de un total de 200 individuos de mejillón Mytilus edulis platensis de entre 5,5 y 6,5 cm de largo total, provenientes de ambos bancos estudiados. La proporción de sexos fue de un $55-57 \%$ de individuos machos y un $40-41 \%$ de individuos hembras, en tanto que un porcentaje reducido de individuos mostraron una condición hermafrodita. La composición de sexos presentó una gran similitud entre ambos bancos (Fig. $6)$.

\section{Banco Justicia}

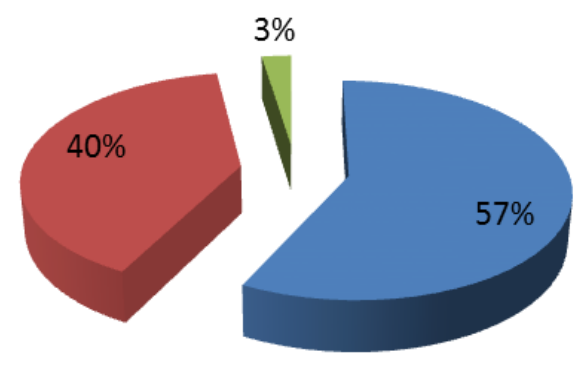

Banco Pta. Caldera

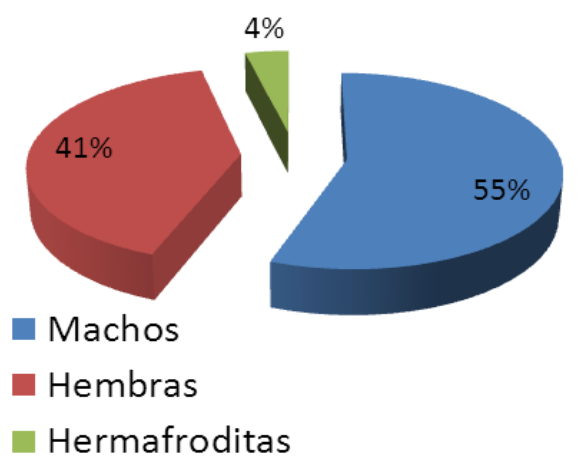

Fig. 6. Proporción de sexos de los individuos analizados

Las muestras de mejillones analizadas presentaron individuos en los diferentes estadios de desarrollo gonadal de la escala de madurez, según la época del año (Fig. 7). Se observó un alto grado de sincronía en los estadios de desarrollo gonadal entre los individuos del mismo banco, que se evidenció por la homogeneidad de estadios sexuales de cada muestra. En el mes de diciembre de 2013, se observó también sincronía entre individuos de los diferentes bancos estudiados, que se encontraron en los estadios de maduración de gametas y de desove.

La fase de maduración tuvo lugar entre agosto y diciembre, observándose en el $100 \%$ de los individuos del mes de septiembre de 2013 en el Banco Justicia y en un 100\% de los individuos del mes de octubre de 2014 en la población de Punta Caldera. Los individuos en estadio de evacuación de gametas se observaron de noviembre a marzo, y alcanzaron el porcentaje más elevado durante los meses de diciembre y febrero. El período de desove fue 
coincidente entre ambos bancos, iniciándose durante el mes de noviembre y extendiéndose hasta el mes de marzo del año siguiente. El máximo de desovantes fue registrado durante el mes de febrero, aunque en los meses de noviembre, diciembre y enero el nivel de desove se mantuvo elevado (Fig. 7).

Una vez desovados, los individuos entraron en fase de post-desove que se registró entre diciembre y abril en el banco de Punta Caldera. Esta fase marca el fin de la época reproductiva, los folículos se observan muy reducidos y casi vacíos. Individuos en la fase de reposo gonadal fueron observados entre abril y junio. Individuos en la etapa de inicio de la gametogénesis fueron observados hacia finales del otoño. En el mes de mayo, casi el $100 \%$ de los individuos analizados inició la gametogénesis, con gónadas con folículos pequeños y abundante tejido conjuntivo con células de reserva (Fig. 7).

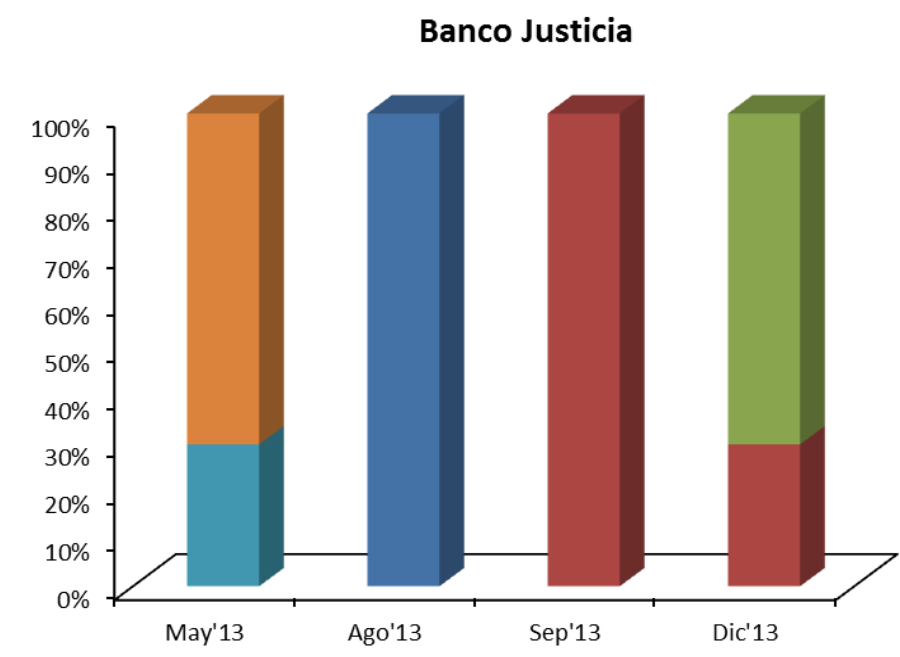

Banco Pta. Caldera

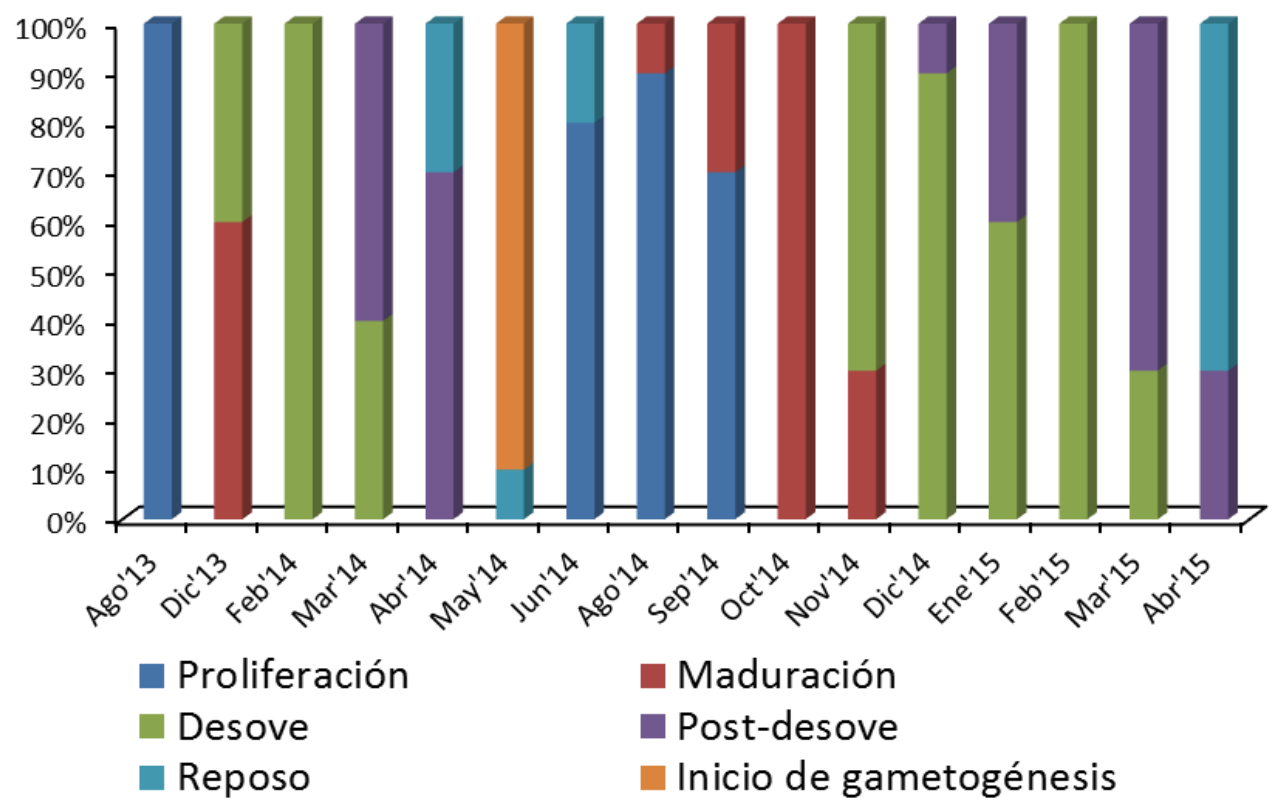

Fig. 7. Porcentaje de individuos en las muestras en los diferentes estadios reproductivos. 
La presencia de larvas (180-230 $\mu \mathrm{m}$ de Lt) en el plancton durante el período de estudio se registró entre diciembre y junio, encontrándose totalmente ausentes en el agua de la bahía de julio a noviembre (Fig. 8). La abundancia máxima de larvas se observó durante el mes de febrero (Kruskal-Wallis $\mathrm{H}=45,51, \mathrm{p}<0,001$ ), en coincidencia con la época de mayor temperatura del agua. La abundancia media de larvas durante febrero de 2014 fue superior a la de febrero de 2015, pero también presentó mayor variabilidad entre muestras. Sin embargo, el análisis estadístico mostró que las diferencias entre febrero de 2014 y febrero de 2015 no fueron significativas (Mann-Whitney $\mathrm{U}$ Test $\mathrm{W}=15, \mathrm{p}=0,1$ ).

El análisis de regresión realizado mostró que la abundancia de larvas en el zooplancton tuvo una correlación positiva significativa con la temperatura del agua $\left(r_{s}=0,71, p<0,001, n=51\right)$ (Fig. 9).

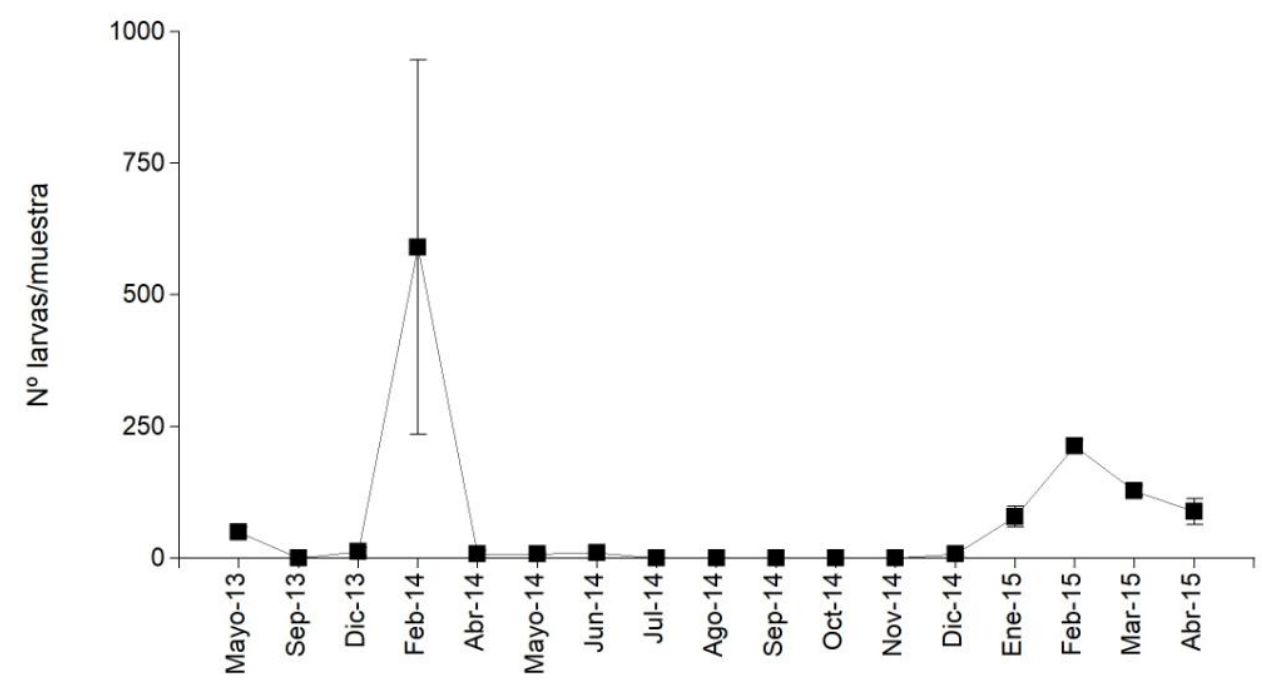

Fig. 8. Abundancia promedio $( \pm \mathrm{ds})$ de larvas de mejillón por muestra de zooplancton.

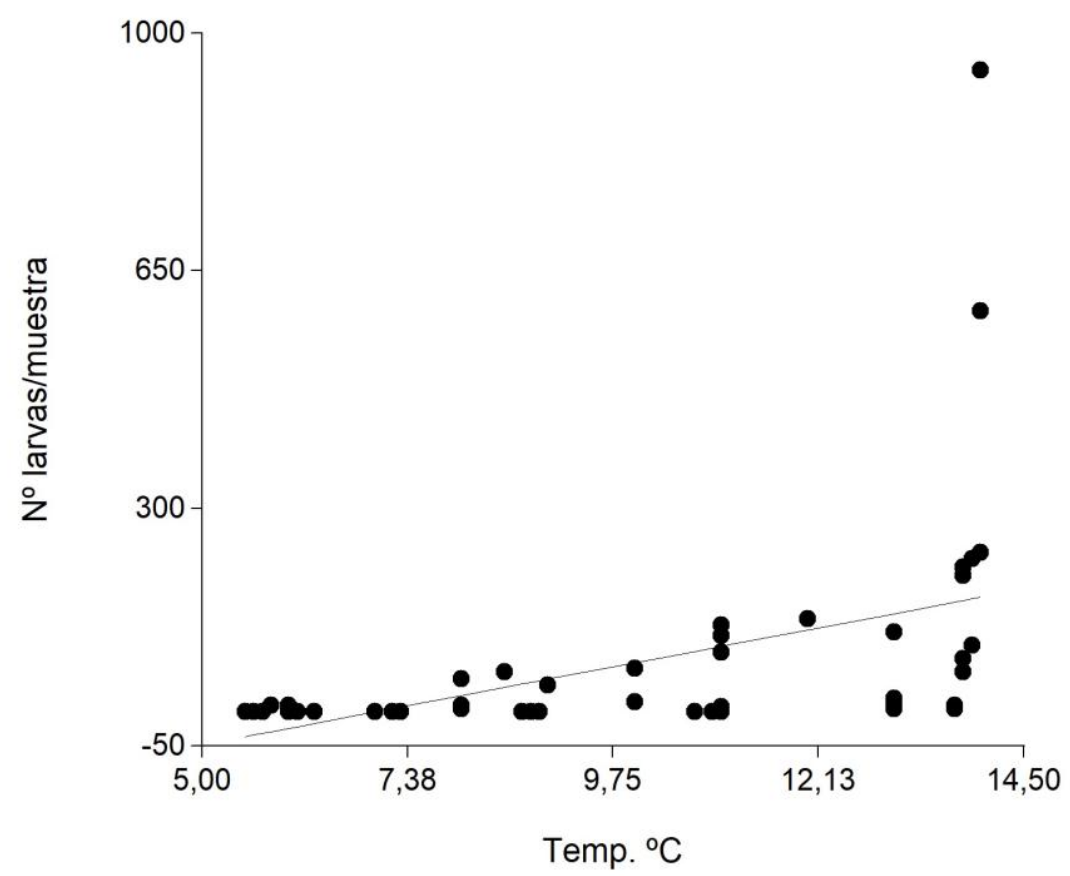

Fig. 9. Regresión lineal simple entre la abundancia de larvas de mejillón en el zooplancton y la temperatura del agua durante el período de estudio $\left(\mathrm{r}_{\mathrm{s}}=0,71, \mathrm{p}<0,001, \mathrm{n}=51\right)$. 
La presencia de individuos juveniles ( $<10 \mathrm{~mm} \mathrm{Lt}$ ) en la población se registró en las cuatro estaciones del año, no pudiendo observarse un patrón temporal definido en el reclutamiento en ninguno de los dos bancos. En el Banco Justicia, no se detectaron diferencias significativas en la abundancia de juveniles entre las distintas épocas relevadas. En el banco de Punta Caldera hubo diferencia significativas en la abundancia de juveniles entre las diferentes épocas (Kruskal-Wallis $\mathrm{H}=15,45, \mathrm{p}=0,008$ ); las abundancias más altas se registraron en diciembre de 2013, marzo y junio de 2014 y febrero de 2015 (Mann-Whitney U Test Dic13=Mar-14=Jun-14=Feb-15>Ago-13=Oct-14, Ago-13=Mar-14) (Fig. 10).

La abundancia más elevada de juveniles se registró en el nivel intermareal medio del Banco Justicia, con un valor máximo de 375 ind. $\mathrm{m}^{-2}$, mientras que en el banco rocoso de Punta Caldera el valor máximo fue de 250 ind. $\mathrm{m}^{-2}$ en el mismo nivel intermareal; sin embargo, la diferencia en la abundancia promedio entre niveles no fue estadísticamente significativa en ninguno de los dos bancos (Fig. 11).
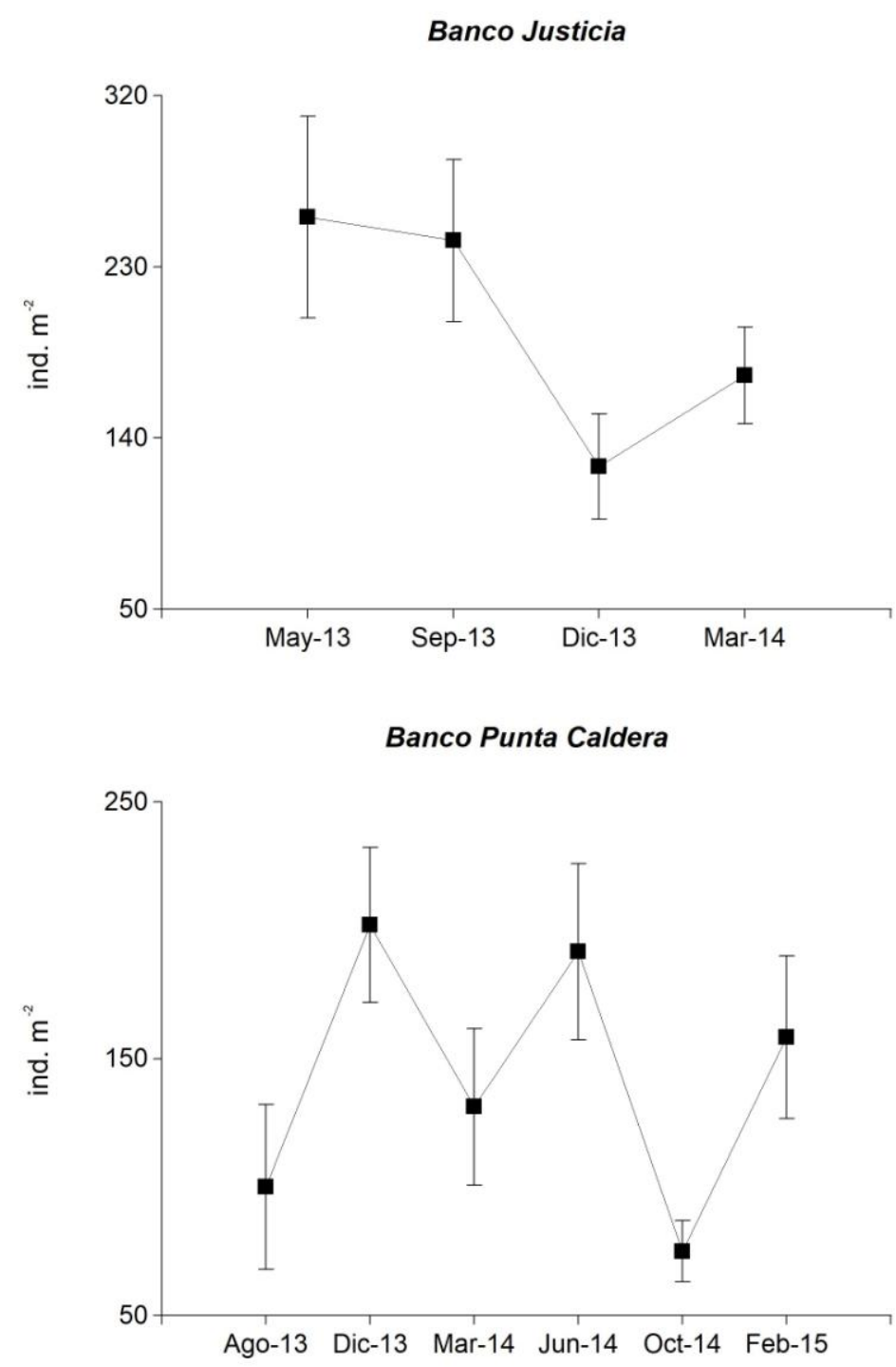

Fig. 10. Abundancia promedio $( \pm \mathrm{ds})$ de reclutas $(<10 \mathrm{~mm} \mathrm{Lt})$ en cada banco en las diferentes épocas. 

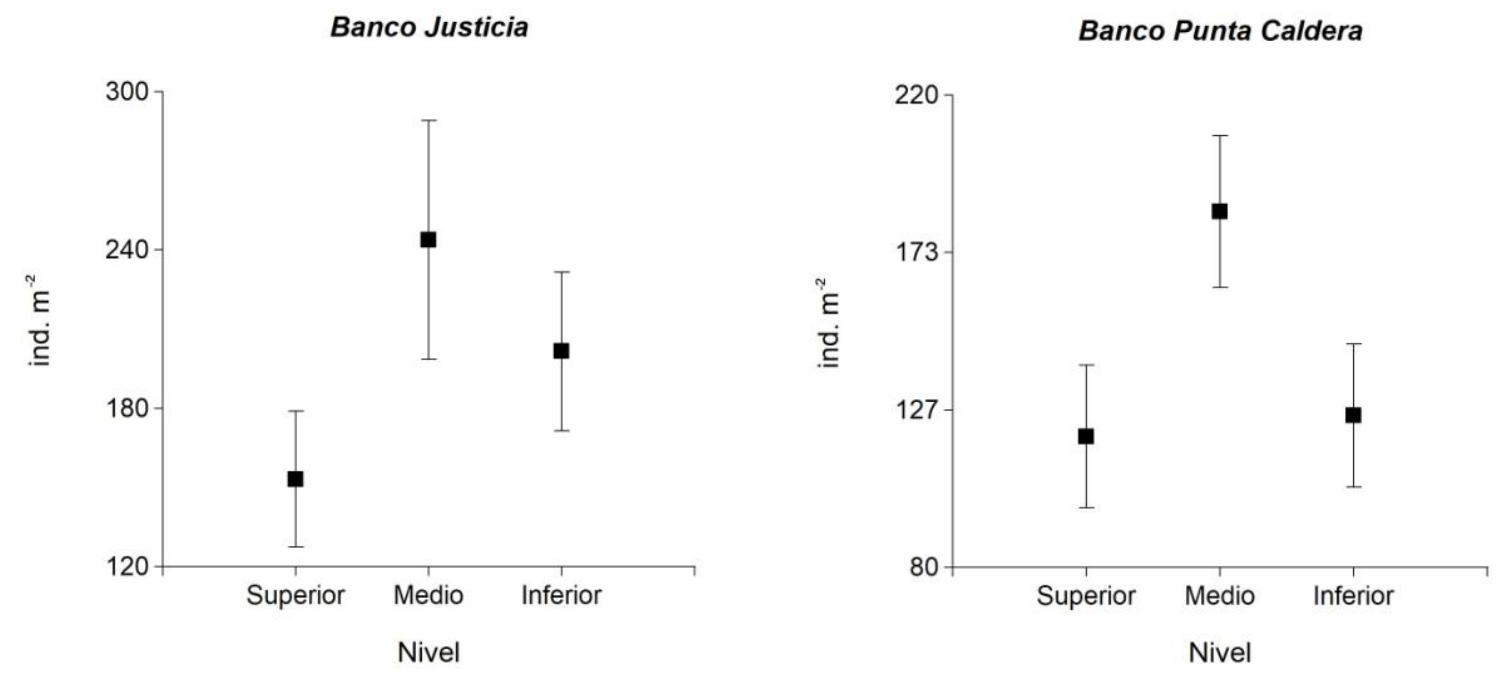

Fig. 11. Abundancia promedio $( \pm \mathrm{ds})$ de reclutas $(<10 \mathrm{~mm} \mathrm{Lt})$ por nivel intermareal en ambos bancos.

La abundancia promedio de juveniles en el Banco Justicia fue significativamente más alta que en el banco de Punta Caldera (Kruskal-Wallis $\mathrm{H}=5,18, \mathrm{p}=0,022$ ) (Fig. 12). Sin embargo, el análisis estadístico post hoc demostró que la abundancia de juveniles fue significativamente más alta que en Punta Caldera sólo en el nivel intermareal inferior (Mann-Whitney U Test $\mathrm{W}=409,5, \mathrm{p}=0,024)$ (Fig. 13).

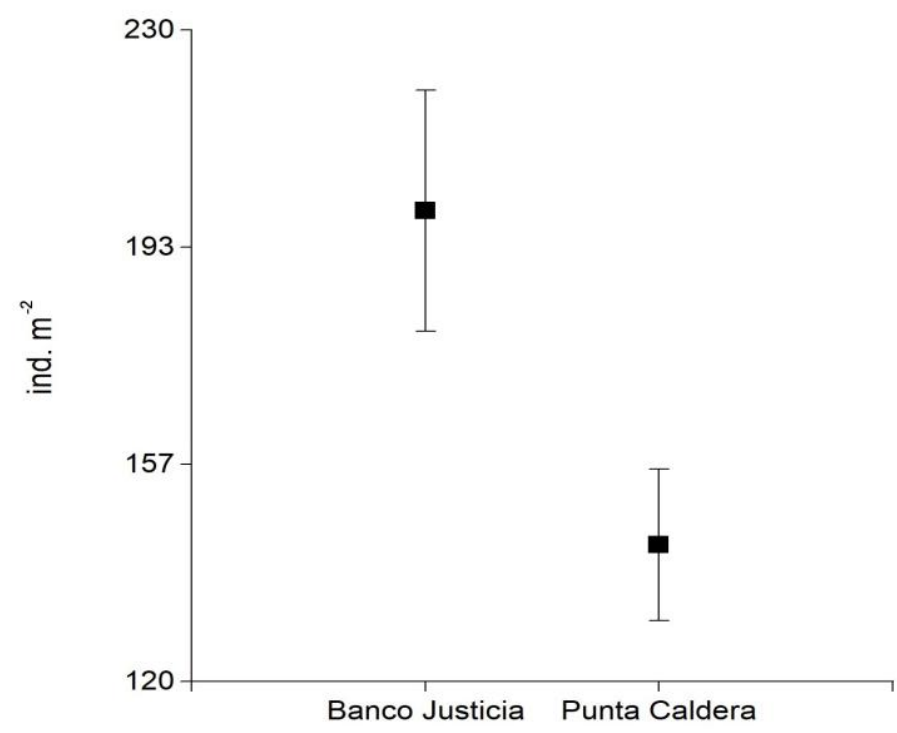

Fig. 12. Comparación de la abundancia promedio $( \pm \mathrm{ds})$ de reclutas $(<10 \mathrm{~mm} \mathrm{Lt})$ entre ambos bancos estudiados. 

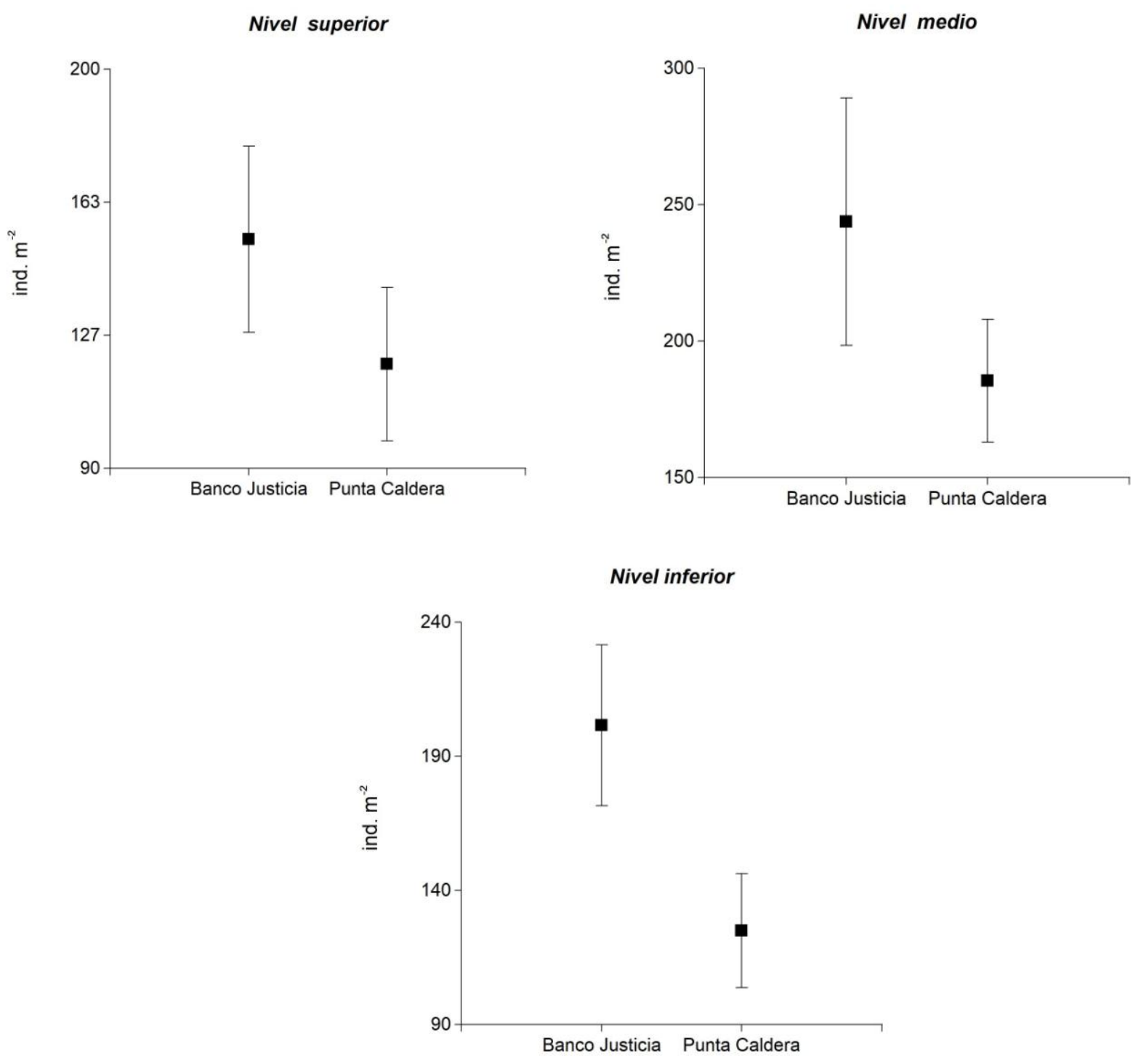

Fig. 13. Comparación de la abundancia promedio $( \pm \mathrm{ds})$ de reclutas $(<10 \mathrm{~mm} \mathrm{Lt})$ entre ambos bancos en los diferentes niveles intermareales.

\section{Discusión}

En la última década, se ha generado una rica bibliografía acerca de la importancia relativa de los procesos pre y post-asentamiento del mejillón, donde todas las etapas de la historia de vida se encuentran involucradas. Sin embargo, el grado de desarrollo del conocimiento de estos procesos es asimétrico en nuestro pais y particularmente en la región de la Patagónia austral, lo que hace que los aportes al respecto sean particularmente importantes para el manejo y la gestión de esta especie de importancia comercial.

Debido a la característica sedentaria de los moluscos bivalvos, los cuales no pueden migrar según preferencias ambientales, estos deben ajustar su ciclo reproductivo a las condiciones oceanográficas reinantes. Este tipo de ajuste determina variaciones anuales en el momento del desove, como así también en la magnitud del mismo. El ciclo reproductivo de Mytilus edulis platensis ha sido estudiado en diversos sitios de la Patagonia (Zaixso, 2008), debido a que presenta variaciones dentro del área de distribución geográfica, mostrando una gran 
plasticidad para adaptarse a diferentes ambientes (Trancart, 1978; Tortorelli, 1987; Vinuesa, 1978; Bala, 1989; Calvo et al. 1998; Oeherens Kissner y Kroeck, 2006; Sar, 2010).

En Bahía San Julián, se observó un alto nivel de sincronismo en el desarrollo gonadal de los individuos de mejillón, que se evidenció por la homogeneidad de estadios sexuales en la población en ambos bancos estudiados en cada época del año. La sincronización en la maduración y liberación de los productos sexuales es un factor crítico para el incremento de las posibilidades de fertilización y producción larvaria exitosa, y en las altas latitudes, donde los cambios ambientales son estacionales, se observa un mayor grado de sincronización en la liberación de gametas, especialmente en especies que producen larvas planctotróficas (Sastry, 1979). Los mejillones se consideran reproductores totales, donde la estacionalidad reduce el período de reproducción anual a pocos meses, en los cuales la masa gonadal se desarrolla en todos los individuos de la población simultáneamente (Urban, 2000).

A diferencia de lo observado en poblaciones más al norte en nuestro país, en Bahía San Julián el desove se produce entre noviembre y marzo, y alcanza su mayor importancia durante el mes de febrero, coincidentemente con la máxima abundancia de larvas en el agua de la bahía. En este sentido, se observa un corrimiento hacia el verano con respecto a las poblaciones submareales de Mar del Plata y Necochea, en dónde el desove se produce principalmente entre septiembre y octubre (Penchaszadeh, 1983). De la misma manera, el período de recuperación de las gónadas y todo el ciclo gonadal se encuentra corrido con respecto a estas localidades, iniciándose la gametogénesis durante el mes de mayo en nuestra área de estudio. Estos resultados son coincidentes con los encontrados por Vinuesa (1978) para Mytilus chilensis (=Mytilus edulis platensis) en la ría de Puerto Deseado (Santa Cruz) que indican que la madurez máxima previa al desove ocurre entre octubre y diciembre, y el período de desove en esa localidad se extiende desde fines de noviembre a mayo. Este autor describe un desove asincrónico para la Ría Deseado, sin embargo, se debe considerar que el grado de sincronización puede variar entre especies y entre poblaciones de una misma especie a lo largo de su área de distribución geográfica (Sastry, 1979). Un período de desove menos extenso estaría relacionado a una mayor amplitud del rango de variación de las temperaturas extremas del agua, que en estas zonas es de $10^{\circ} \mathrm{C}\left(4^{\circ}-14^{\circ} \mathrm{C}\right)$.

Trancart (1978) describió, para poblaciones infralitorales del Golfo San José (Chubut), dos pulsos de emisión de gametas, uno de mayor intensidad en agosto-setiembre y otro en noviembre-diciembre. Por otra parte, Bala (1991) describió también para el Golfo San José, que la emisión de gametas puede ser uni o bimodal. La primera se produce entre los meses de septiembre-diciembre en el infralitoral, mientras que en el mesolitoral se produce entre septiembre y noviembre. Los picos bimodales se detectaron en julio-agosto y diciembre, y entre septiembre-octubre y enero, en los ambientes infra y mesolitoral respectivamente.

Los ciclos reproductivos de muchas especies de invertebrados marinos están influenciados bajo una compleja interacción entre factores exógenos (propios de donde habitan) especialmente la temperatura, salinidad, luz y alimentación- y factores endógenos (propios del organismo) como la reserva de nutrientes, ciclos hormonales y genoma, entre otros (Sastry, 1975). Los factores ambientales actúan sobre el desarrollo gonadal influyendo en los mecanismos internos y sincronizando la actividad reproductiva desde el inicio de la gametogénesis hasta la puesta (Sastry, 1979). De estos factores, la temperatura es considerada como uno de los estímulos centrales que provocan la liberación de gametas en los bivalvos y, generalmente, existe un umbral térmico por encima del cual la evacuación ocurre (Sastry, 1979). Por otra parte, Lubet (1959) sugiere que el desove en Mytilus edulis es controlado por una combinación de factores internos y externos. En las costas de Gran Bretaña, la temperatura determina, directamente o indirectamente, la liberación de gametas y también influye sobre la intensidad de la liberación (Chipperfield, 1953; Bayne, 1976). Bala (1989) 
describe para el Golfo San José que al descender la temperatura por debajo de los $13{ }^{\circ} \mathrm{C}$ comienzan a desarrollarse los folículos, llegando a la madurez total en épocas de bajas temperaturas, mientras que el desove se intensifica a medida que aumenta la temperatura, con picos de emisión a $12^{\circ} \mathrm{C}$.

El pico en la abundancia de larvas, observado en el plancton durante el mes de febrero, permite inferir que la época de mayor asentamiento de larvas y de mayor reclutamiento de juveniles en Bahía San Julián se produciría durate fines de verano y principios de otoño. Sin embargo, la abundancia de juveniles en la poblacion fue en general irregular a lo largo del tiempo y poco previsible en los bancos estudiados. La fase larvaria, extendida en el espacio pero restringida temporalmente, es la etapa más crítica y menos conocida de la historia de vida de los bivalvos en Patagonia, y un cuello de botella en la renovación de individuos en los bancos que componen las poblaciones. Sobre ella actúan una multiplicidad de factores ambientales que hacen del reclutamiento una de las etapas mas imprevisibles y variables del ciclo de vida. Para la mayoria de los invertebrados marinos, el número de larvas que luego de la metamorfosis logran fijarse al sustrato e incorporarse a la población de adultos depende no sólo de la cantidad de larvas presentes en el plancton sino también de su tasa de supervivencia previa al asentamiento. Durante la fase pelágica, las larvas también pueden ser llevadas por las corrientes y dispersadas lejos de la población adulta que les dio origen (Conell y Gillanders, 2007). Todos estos factores hacen de la etapa de reclutamiento un proceso particularmente imprevisible y difícil de anticipar en el mejillón y en los invertebrados marinos en general.

La abundancia de juveniles en los bancos durante el período de estudio en Bahía San Julián no mostró un patrón temporal definido, evidenciando un alto grado de imprevisibilidad. Si bien, la abundancia de individuos juveniles fue en general más alta durante los meses de verano, también se observaron abundancias elevadas durante los meses de invierno. Esto último puede explicarse como resultado de la permanencia en los bancos de los juveniles reclutados a fines del verano y durante el otoño, cuyo ritmo de crecimiento es muy lento o se encuentra detenido durante los meses más fríos. Los valores más bajos de juveniles registrados a fines de invierno y en primavera en Punta Caldera se corresponden con el crecimiento de esos mismos juveniles, que pasarían a integrar las clases de talla superiores a los $10 \mathrm{~mm}$ de Lt. Esto coincide también con la ausencia de reclutamiento durante el invierno. Sin embargo, para confirmar estas observaciones, deberían realizarce muestreos mensulaes a lo largo de al menos dos período anuales completos, que permitan determinar la intensidad del reclutamiento a lo largo del año y la tasa de crecimiento de los juveniles en las diferentes épocas en la Bahía San Julián.

\section{CONCLUSIONES}

- $\quad$ Durante el período de estudio se observó un alto grado de sincronismo en los estadios de madurez gonadal entre los individuos de la población de Mytilus edulis platensis de Bahía San Julián.

- $\quad$ En Bahía San Julián, el mejillón Mytilus edulis platensis efectuó la evacuación de gametas desde fines de primavera hasta fines de verano durante el período de estudio.

- Las larvas presentaron su mayor abundancia en el plancton durante el mes de febrero, cuando la temperatura del agua alcanzó su valor máximo, si bien la concentración de las mismas fue variable de un año a otro. 


\begin{abstract}
- $\quad$ La abundancia de juveniles en la población fue en general irregular a lo largo del año y poco previsible en los bancos de Bahía San Julián, pudiendo ser el resultado del proceso de reclutamiento y del ritmo de crecimiento de los individuos juveniles según la época del año.

- La abundancia promedio de juveniles en el Banco Justicia, de sustrato fangoso, fue superior a la registrada en el banco de Punta Caldera de sustrato rocoso, siendo significativamente más alta en el nivel intermareal inferior.
\end{abstract}

\title{
5. AGRADECIMIENTOS
}

Los autores desean agradecer a la Subsecretaría de Pesca y Actividades Portuarias de la Provincia de Santa Cruz por el préstamo del micrótomo utilizado para la realización de los cortes histológicos, y a las autoridades del Puerto de San Julián y de la Prefectura San Julián por autorizar y facilitar el ingreso a las instalaciones del muelle para la toma de muestras de zooplancton. El presente informe es resultado del proyecto de investigación 29D/051 "Ciclo reproductivo y reclutamiento del mejillón en bancos naturales de Santa Cruz (Argentina)" financiado con fondos de la Universidad Nacional de la Patagonia Austral.

\section{BIBLIOGRAFÍA}

BALA, L.O. (1989). Biología y ecología del mejillón (Mytilus edulis platensis) en el Golfo San José, Prov. de Chubut. PhD Dissertation, Universidad Nacional de la Plata, Buenos Aires, Argentina. $187 \mathrm{pp}$.

BALA, L.O. (1991). Ciclo sexual del mejillón (Mytilus edulis platensis) del golfo San José. Resúmenes Jornadas Nacionales de Ciencias del Mar, Puerto Madryn, 1991: 4.

BALA, L.O. (1996). Edad y crecimiento de Mytilus edulis platensis d'Orbigny, 1846, en el golfo San José, Argentina. Biol. Pesq., 25, 59-66.

BAYNE, B.L. (1976). Marine mussels: their ecology and physiology. International Biological Programme 10. London- N.Y. 410 pp.

CALVO, J., E.MORRICONI y P.M. ORLER (1998). Estrategias reproductivas de moluscos bivalvos y equinoideos. En: E. Boschi (Ed). El Mar Argentino y sus recursos pesqueros: Tomo 2. Moluscos de interés pesquero. Cultivos y estrategias de bivalvos y equinoideos. INIDEP Mar del Plata: 195-231.

CHIPPERFIELD, P.N.J. (1953). Observations on the breeding and settlement of Mytilus edulis (L.) in british waters. J. Mar. Biol. Ass. U.K. 32: 449-476.

CONELL, S. y B. GILLANDERS (2007). Marine ecology. Oxford University Press, Oxford, $629 \mathrm{pp}$.

FALABELLA, V., C. CAMPAGNA y J. CROXALL (Eds.) (2009). Atlas del Mar Patagónico. Especies y Espacios. Buenos Aires, Wildlife Conservation Society y BirdLife International. http://www.atlas-marpatagonico.org.

GOSLING, E. (1992). The mussel Mytilus: Ecology, Physiology, genetics and culture. ELSEVIER, Amsterdam, 589 pp.

ITUARTE, C, J.P. MARTIN y D.G. ZELAYA (2012). A new species of Mysella from Patagonia (Bivalvia: Galeommatoidea). The Nautilus 126 (4): 136-142.

KÜHNEMANN, O. (1976). Observaciones ecológicas sobre la vegetación marina y terrestre de la Isla de los Estados (Tierra del Fuego, Argentina). Ecosur, 3 (6): 121-248.

LASTA, M.L., N.F COICCO, C.BREMEC y A.M. ROUX (1998). Moluscos bivalvos y gasterópodos. En: E. Boschi (Ed.) El Mar Argentino y sus recursos pesqueros: volumen 
2. Los moluscos de interés pesquero. Cultivos y estrategias reproductivas de bivalvos y equinoideos. INIDEP, Mar del Plata, pp. 231.

LUBET, P. (1959). Recherches sur le cycle sexuel et l'émission des gamètes chez les Mytilides et les Pectinides (Mollusques Bivalves). En: Villalba Garcia, A. 1995. Estudio de la Marteiliasis del Mejillón. Efectos de esta enfermedad en el mejillón cultivado en las Rías Gallegas. Tesis Doctoral, Instituto de Investigaciones Marinas, Xunta de Galicia (España), 139 pp.

MARTIN, J.P., A. GARESE, A. SAR y F. ACUÑA (2015). Fouling community dominated by Metridium senile (Cnidaria, Anthozoa, Actiniaria) in Bahía San Julián (Southern Patagonia, Argentina). Scientia Marina 79 (2), DOI: http://dx.doi.org/10.3989/scimar.04082.21A.

MORSAN, E (2007). Pesquerías de moluscos bivalvos y gasterópodos en el Mar Argentino. Atlas de Sensibilidad Ambiental de la costa y el Mar Argentino, Boltovskoy D. (Ed.). http://atlas.ambiente.gov.ar.

MORSAN, E.M. y P.C, ZAIDMAN (2009). Scale, dynamic and management in the harvesting of mussel in north Patagonia (Argentina). Chapter 6 En: McManus NF, Bellinghouse DS (eds) Fisheries: management, economics and perspectives. Nova Science Publishers, New York, NY, p 171-197

NOAA (1983). Histological Techniques for Marine Bivalve Molluscs. U.S. Department of Commerce, National Oceanic and Atmospheric Administration. National Marine Fisheries Service, Woods Hole, Massachusetts, $97 \mathrm{pp}$.

OHERENS KISSNER, E. y M.A. KROECK (2006). Determinación de la talla de primera madurez sexual del mejillón, Mytlus edulis platensis, en el Golfo San Matías. Serie Publicaciones IBMP 4: 21-44

PENCHASZADEH, P.E. (1974). Ecología del mejillón Mytilus platensis d'Orbigny de bancos circalitorales. PhD Dissertation, Universidad, Facultad de Ciencias Exactas y Naturales, Buenos Aires, Argentina, $187 \mathrm{pp}$.

PENCHASZADEH, P.E. (1983). Ecología larvaria y reclutamiento del mejillón del Atlántico suroccidental, Mytilus platensis d'Orbigny. Cahiers Biol. Mar. 21:169- 180.

RAMORINO, L y B. CAMPOS (1983). Larvas y postlarvas de mytilidae de Chile (Mollusca: Bivalvia). Rev. Biol. Mar., Valparaiso 19 (2): 143-192.

SAR, A. (2010). "Distribución batimétrica, demografía y producción de Mytilus edulis platensis en la bahía de San Julián, Patagonia, Argentina". Tesis de Magíster en Ciencias mención Manejo y Conservación de Recursos Naturales en Ambientes Subantárticos. Universidad de Magallanes, $86 \mathrm{pp}$.

SASTRY, A.N. (1975). Physilogy and ecology of reproduction in marine invertebrates. En "Physiological ecology of estuarine organisms" (F.J. Vernberg, ed.), Univ. of South Carolina Press, Columbia: 279-299.

SASTRY, A.N (1979). Pelecypoda (excluding ostreidae). En: Giese A.C. and J.C. Pearse (eds). Reproduction of marine invertebrates. Academic Press, New York: 113-192.

SERVICIO DE HIDROLOGÍA NAVAL (S.H.N.) (2009). Tablas de Marea de Puerto San Julián. http://www.hidro.gov.ar/oceanografia/Tmareas/Form_Tmareas.asp.

TORTORELL, M.C. (1987). Contribución al estudio de los ciclos reproductivos del mejillón patagónico, Mytilus chilensis (Hupe), y de la cholga Aulacomya ater (Molina), en el canal de Beagle. Tesis doctoral. Universidad Nacional de Buenos Aires, 257 pp.

TRANCART, M. (1978). Biologie et possibilités d'exploitation de Mytilus platensis d'Orb. dans le golfe San José, peninsule Valdés, Argentine. These de Doctorat de 3ème Cycle, Ocenologie. U.E.R. des Sciences de la Mer et de l'environnement (Université D'AixMarseille II), 85 pp. 
URBAN, J.H. (2000). Métodos y conceptos de la ecología de poblaciones con énfasis en la dinámica poblacional de invertebrados y peces marinos. Universidad Del Valle, Cali. $181 \mathrm{pp}$.

VILlALBA, A. (1995). Estudio de la Marteiliasis del Mejillón. Efectos de esta enfermedad en el mejillón cultivado en las Rías Gallegas. Tesis Doctoral, Instituto de Investigaciones Marinas, Xunta de Galicia (España), 139 pp.

VINUESA, J.H. (1978). Ciclo gonadal y primera madurez sexual del mejillón patagónico Mytilus edulis chilensis Hupe de Pto. Deseado. Physis (Buenos Aires), 38 (95):35- 47.

ZAIXSO, H.E., A.L. BORASO DE ZAIXSO y J.J. LÓPEZ GAPPA (1978). Observaciones sobre el mesolitoral rocoso de la zona de Ushuaia (Tierra del Fuego) Argentina. Ecosur 5: $119-130$.

ZAIXSO, H.E. (1999). Distribución submareal del mitílido Aulacomya atra atra (Molina) en el Golfo San José (Argentina) en relación a la profundidad, características del fondo y condiciones hidrográficas. Physis, Sección A, 57 (132-133): 1-10.

ZAIXSO, H.E. (2004). Bancos de cholga Aulacomya atra atra (Molina) (Bivalvia: Mytilidae) del golfo San José (Chubut, Argentina): Diversidad y relaciones con facies afines. Revista de Biología Marina y Oceanografía (Chile) 39: 61- 78.

ZAIXSO, H. (ed.) (2008). Informe Técnico Pesca Artesanal y Acuicultura para la Agencia de Desarrollo Sustentable de Puerto San Julián. Puerto San Julián, Santa Cruz, Argentina, $382 \mathrm{pp}$.

ZAR, J.H. (1996). Biostatistical analysis. Prentice Hall, New Jersey. 